\title{
DIVERGÊNCIAS E CHÃO COMUM: O DIREITO À EDUCAÇÃO NO IV SEMINÁRIO DE EDUCAÇÃO BRASILEIRA*
}

\author{
MAURÍ́cIo ÉRNICA**
}

\begin{abstract}
RESUMO: Este artigo aborda debates ocorridos no IV Seminário de Educação Brasileira (IV SEB), promovido pelo Centro de Estudos Educação e Sociedade (Cedes), em fevereiro de 2013, na Unicamp. Seu objetivo é caracterizar alguns temas e posições que estiveram em jogo para, deles, inferir elementos gerais do debate contemporâneo sobre a educação brasileira que possam contribuir para a caracterização do chão comum no qual nos movemos. Dentre os temas tratados no Seminário, foram destacados: a definição de direito à educação de qualidade, as formas de sua verificação e de responsabilização dos agentes que devem assegurá-lo.
\end{abstract}

Palavras-chave: Seminário de Educação Brasileira. Direito à educação. Desigualdades educacionais. Avaliação educacional. Responsabilização educacional.

\section{DIVERGENCIES AND COMMON GROUND:}

EDUCATION RIGHTS AT THE IV BRAZILIAN EDUCATION SEMINAR

ABSTRACT: This article addresses discussions occurred in the IV Brazilian Education Seminar (IV SEB) held by the Education and Society Studies Center (Cedes), in February 2013, at Unicamp. It primarily aims to categorize some of the subjects and positions in place as a starting point to infer the general elements of contemporary debates on Brazilian education which might contribute to the arrangement of the common ground we move on. Amongst the subjects discussed in the seminar, the following should be highlighted: the definition of quality education rights, ways to authenticate and charge responsible agents which should be accountable for them.

Key words: Brazilian Education Seminar. Education rights. Education inequalities. Education evaluation. Accountability.

Agradeço a Ana Maria F. Almeida, Ivany Rodrigues Pino, José Francisco Soares, Luci Banks-Leite, Luiz Carlos de Freitas, Maria Alice Setubal e Mariane Campelo Koslinski pela leitura crítica que fizeram das versões preliminares deste artigo. Procurei incorporar suas sugestões e a eles devo algumas das ideias expostas. Evidentemente, eles não são responsáveis pelas teses aqui defendidas e tampouco pelas insuficiências do resultado final.

* Universidade Estadual de Campinas (Unicamp). Campinas (SP) - Brasil.

Contato com o autor: <ernica@unicamp.br> 


\section{DivergenCES ET SEUIL COMMUN: LE DROIT A}

L'ÉDUCATION DANS LE IV SEMINAIRE D'ÉDUCATION BRÉSILIENNE

RÉSUMÉ: Cet article aborde des débats produits tout au long du IV Séminaire d'Éducation Brésilienne (IV SEB), promu par le Centre d'Études de l'Éducation et de la Société (Cedes), en février 2013, à l'Unicamp. Son objectif est caractériser quelques sujets et positions qui ont été abordés pour inférer des éléments généraux du débat contemporain sur l'éducation brésilienne qui peuvent contribuer à la caractérisation du seuil commun sur lequel nous nous déplaçons. Parmi les sujets traités dans le Séminaire, ils ont été soulignés: la définition de droit à l'éducation de qualité, les formes de sa vérification et de responsabilisation des agents qui doivent l'assurer.

Mots-clés: Séminaire d'Éducation Brésilienne. Droit à l'éducation. Inégalités scolaires. Évaluation scolaire. Responsabilisation scolaire.

\section{Apresentação}

$\mathrm{E}$ ntre os dias 20 e 22 de fevereiro de 2013, o IV Seminário de Educação Brasileira (IV SEB) reuniu, na Universidade Estadual de Campinas (Unicamp), uma ampla gama de pesquisadores da área educacional e das ciências sociais, gestores de políticas públicas, parlamentares, assessores parlamentares, representantes de movimentos da sociedade civil e professores da rede pública. A amplitude dos temas debatidos e a diversidade de posições ali presentes marcaram mais essa edição do Seminário como um espaço importante no debate educacional brasileiro.

Esse texto procura caracterizar alguns temas e posições que estiveram em jogo durante o IV SEB para, deles, inferir elementos gerais que possam contribuir para a caracterização do chão comum do debate educacional brasileiro. Entre os temas tratados no Seminário, serão abordados: a definição de direito à educação, as formas de sua verificação e as de responsabilização dos agentes que devem assegurá-lo.

Os debates do IV SEB deram-se na interface entre os campos científico e político, recusando a dissociação entre a interpretação científica e a atuação política sobre a realidade educacional. Ainda que esses dois campos decisivos para a formulação de políticas públicas educacionais mantenham várias zonas de intercomunicação e mesmo havendo agentes atuantes nesses dois domínios, os dois campos têm lógicas de funcionamento distintas, impondo a seus agentes compromissos, objetivos e interlocutores distintos, que nem sempre são reconhecidos e legitimados mutuamente, o que pode ampliar o conflito entre eles e reduzir as possibilidades de cooperação.

No Seminário, como parte da construção de seu chão comum, além da concordância sobre a relevância dos tópicos em questão, partilhou-se consensos sobre princípios de constituição desse campo de confluência. Em primeiro lugar, afirmou-se 
reiteradamente a necessidade da controvérsia para a qualidade, o desenvolvimento e a legitimação dos debates políticos e científicos. Em segundo lugar, foi dada grande importância às evidências empíricas como elementos centrais tanto das pesquisas científicas, como para o embasamento das políticas públicas. Em terceiro lugar, foram valorizadas as pesquisas científicas que, além de serem teórica e metodologicamente bem formuladas, buscam influenciar políticas públicas. Em quarto lugar, reivindicou-se em vários momentos que as políticas busquem subsídios nos conhecimentos científicos e se submetam à sua análise crítica.

Os conflitos entre as duas atividades constitutivas desse terreno híbrido também foram abordados. Em debate com José Francisco Soares, Choukri Ben Ayed lembrou que, em seu país, os estudos científicos frequentemente são usados como instrumentos de legitimação de políticas. Como estudos diferentes, feitos a partir de escolhas teóricas e metodológicas diversas, podem levar a resultados distintos, não raro, portanto, os gestores aderem àqueles que lhes são mais favoráveis. Para reduzir os riscos da instrumentalização do campo científico pelo político, a posição defendida pelos pesquisadores foi que as políticas públicas deveriam ser avaliadas e escrutinadas por pesquisas diferentes, oriundas de posições teóricas e metodológicas diferentes, sendo que todas essas investigações precisariam se submeter à avaliação dos pares, nas instâncias científicas autorizadas.

Em suma, defendeu-se que o diálogo e a colaboração entre os campos precisariam ocorrer de modo que o campo científico se mantenha relativamente autônomo, permitindo que diferentes posições disputem, segundo critérios científicos, a validade de suas formas de descrever e interpretar os fenômenos educacionais. Isso implica reconhecer que as disputas científicas não podem ser reduzidas a posições políticas e, sendo assim, os textos científicos devem ser interpretados, validados ou refutados a partir de atributos intrínsecos à atividade científica.

\section{Disputas em torno do direito à educação: definições do direito, instrumentos para verificar o seu cumprimento e formas de res- ponsabilização}

\section{Direito à educação e qualidade da oferta educacional}

A atividade política e a educativa requerem definições normativas que determinem o sentido que devem assumir as transformações visadas, além de instrumentos para sua realização e para a verificação de resultados. Essas definições e esses meios, muito embora possam ser subsidiados e escrutinados pela literatura científica, são estabelecidos e implementados em disputas políticas. 
O campo político educacional brasileiro, atualmente, traz marcas das mudanças pelas quais o país vem passando desde o processo de redemocratização. Com a reorganização das instituições do Estado democrático, após o período de regime militar, a atuação política no campo educacional se complexificou. Ao mesmo tempo em que assumiu progressivamente uma maior institucionalização, dando-se no interior de cada um dos três poderes e no âmbito das relações entre estes, novos sujeitos entraram no jogo político educacional.

Como pontuou Salomão Ximenes (2013), durante a redemocratização, uma das formas de luta pela afirmação do direito à educação foi a influência na elaboração dos novos marcos legais, atuando-se junto ao Legislativo e ao Executivo. Ao se buscar o avanço pelas leis, com destaque para a Constituição Federal de 1988 e os debates a respeito da Lei de Diretrizes e Bases da Educação (LDB), nos anos 1990, apostou-se que elas seriam instrumentos importantes para a definição de direitos e responsabilidades e, por meio disso, para a indução de políticas que os efetivassem. Outra mudança, decorrente da primeira, é que o campo educacional tem passado por um processo de judicialização da disputa política, sendo que, cada vez mais, o Ministério Público, movimentos sociais institucionalizados, outros grupos políticos e mesmo famílias, valendo-se do caráter normativo dos marcos legais, procuram acionar as cortes judiciais para que seja assegurado o direito à educação.

É nesse novo contexto político-institucional que são disputados sentidos para noções centrais, como a de direito à educação, noção à qual se relacionam, e de certa forma derivam, outras noções igualmente polissêmicas, como a de verificação do cumprimento desse direito e a de responsabilidade educacional.

No Seminário, houve um relativo consenso sobre as dimensões que caracterizam o direito à educação: o acesso à escola, a permanência no sistema com aprovação e a aprendizagem. Não houve divergências significativas sobre as duas primeiras dimensões, sendo que o debate caminhou para a descrição dos grupos ainda não atendidos, destacando-se a maior exposição dos jovens de 15 a 17 anos à reprovação e à evasão escolar. A terceira dimensão do direito à educação, a aprendizagem, suscitou mais discussões.

Apesar do consenso geral de que as aprendizagens cognitivas, que tradicionalmente são objeto das avaliações externas, são condições necessárias e imprescindíveis desse direito, destacou-se em diversos momentos, em diferentes intervenções, que elas não esgotam sequer o conjunto das aprendizagens cognitivas do currículo e, ainda menos, o conjunto das aprendizagens que devem ser asseguradas pela escola básica.

Uma vez que abordam condições necessárias - e fundamentais - do direito à educação, os resultados quantitativos das avaliações externas podem ser instrumentos 
importantes de verificação desse direito. Porém, a ausência de discussões aprofundadas sobre o que as sínteses numéricas significam, no quadro das aprendizagens escolares que se quer assegurar como direito, alimenta sua reificação.

Tomadas como realidades em si, as sínteses numéricas acabam por ocultar o que deveriam revelar e não contribuem para o debate de questões como: quais são as habilidades medidas e qual o seu lugar no conjunto das aprendizagens escolares que se quer assegurar por direito? Como registrar, medir e avaliar a efetiva realização desse conjunto de aprendizagens? Quais são essas aprendizagens multidimensionais que devem ser transmitidas pela escola e quais os seus significados sociais, culturais, econômicos e políticos?

A abordagem dessas questões pode ser situada em um quadro mais geral, igualmente obliterado pela reificação dos números educacionais: qual a cultura geral que a escola deve transmitir como direito? O que confere sua legitimidade? Como ela se relaciona com a diversidade cultural do país? Como se relaciona com as desigualdades sociais definidas, em larga medida, pelas diferenças de apropriação das culturas de prestígio? Como transmiti-la, tendo em vista as desigualdades definidas pela posição das famílias na estrutura social?

Os debates sobre essas três dimensões (oferta, permanência, aprendizagem) que definem a realização do direito à educação das crianças e adolescentes se ligam, diretamente, à discussão sobre a qualidade da oferta educacional, outra noção multidimensional.

Uma primeira dimensão da qualidade da oferta educacional foi definida pelos recursos financeiros diretamente alocados nas redes de ensino. Os dados apresentados por José Marcelino de Rezende Pinto (2013) mostram que a distribuição de recursos para os entes da Federação, por meio do Fundo para o Desenvolvimento da Educação Básica (Fundeb), tem conseguido evitar o pior, reduzindo as desigualdades originais.

Considerando-se os recursos complementares, temos, em 2011, nove estados recebendo o valor mínimo, $\mathrm{R} \$ 1.729,00$ anuais por estudante, sendo que o maior valor representa 1,7 vezes o menor. Se não fossem considerados os recursos complementares da União, teríamos dez estados com recursos iguais ou menores que $\mathrm{R} \$ 1.729,00$. Sem que os repasses sejam considerados, o valor máximo observado (Roraima, com $\mathrm{R} \$ 2.915,00$ ) representa 3,18 vezes o valor mínimo (Maranhão, com R\$ 915,00).

Muito embora o Fundeb reduza as desigualdades entre os estados, Pinto argumenta que ele não é o bastante para assegurar recursos suficientes para a oferta educacional de qualidade. Utilizando-se como referência o Custo Aluno/Qualidade inicial (CAQi) para definir esse patamar de suficiência, o pesquisador sustenta que 
os gastos médios com o Fundeb ( $\mathrm{R} \$ 1.698,00$, com dados de 2010) representam 61\% do CAQi (R\$ 2.757,00, com dados de 2011). Com isso, argumenta favoravelmente à ampliação dos recursos destinados à educação pública.

A defesa do aumento dos gastos em educação pública foi objeto de duas ponderações. Em primeiro lugar, destacou-se que é forçoso compatibilizar a demanda por aumento de gastos com a disponibilidade efetiva de recursos. O horizonte possível, assim, é a destinação de recursos obtidos com os royalties do petróleo extraído da camada pré-sal para a educação pública.

Em segundo lugar, mesmo aceitando a associação entre o volume de gastos por aluno entre diferentes países e seu desempenho médio em provas padronizadas internacionais, como o Programme for International Student Assessment (Pisa), alegou-se que não se pode inferir um nexo causal necessário entre o aumento de recursos em educação pública e a melhoria dos resultados das escolas. Para sustentar empiricamente essa afirmação, os defensores dessa posição mostram dados que revelam a associação fraca entre o gasto de estados e municípios por aluno e o resultado das escolas públicas, controlado o efeito do nível socioeconômico do corpo discente. Por isso, sustentam, é necessário discutir as condições pelas quais a ampliação dos recursos investidos se transformaria em melhores condições para a aprendizagem dos alunos.

Não raro, o debate sobre a relação entre o volume de gastos em educação pública, a definição de prioridades e a eficácia desses investimentos gera uma espécie de impasse, como se não fosse possível considerar, a um só tempo, aspectos das diferentes argumentações.

Há evidências suficientes da necessidade de ampliação de investimentos, quando consideramos outros elementos utilizados para a caracterização da qualidade da oferta educacional, como infraestrutura escolar, formação de professores e salário dos profissionais da educação.

Soares Neto et al. (2013) analisaram 194.932 escolas, rurais e urbanas, públicas e privadas. Os autores propõem um modelo com 22 variáveis, relativas tanto à infraestrutura básica como à infraestrutura de uso pedagógico, e criam uma escala de quatro níveis: elementar, básico, adequado e avançado. No conjunto observado, apenas 15,5\% das escolas têm estrutura adequada ou avançada, percentual que é maior nas regiões Sul e Centro-Oeste (maior que 30\%) e nas escolas da rede federal $(62,5 \%)$. A pior situação é a das escolas rurais, das quais apenas 1,3\% possui infraestrutura adequada ou avançada.

A infraestrutura escolar, inclusive os seus elementos de uso pedagógico, é um direito básico que deveria ser atendido antes de qualquer discussão sobre a sua eficácia. Não cabe discussão sobre a necessidade de se assegurar às escolas água, 
esgoto, banheiro e eletricidade. No que diz respeito à infraestrutura de uso pedagógico, como internet, bibliotecas, laboratórios e quadras, o debate sobre a eficácia de seu uso deve pressupor sua existência.

No que diz respeito à formação de professores, Thiago Alves (2013) apresentou evidências da necessidade de investimentos, baseando-se em dados do Censo Escolar de 2010. Mesmo nas regiões mais ricas (Sudeste, Sul e Centro-Oeste) cerca de $23 \%$ dos docentes não possuem formação universitária. Nas regiões mais pobres do país, os docentes com formação não universitária somam mais da metade do total.

Ao analisar os dados referentes à adequação da formação dos docentes em relação à disciplina que lecionam, e considerando apenas os docentes dos anos finais do ensino fundamental e do ensino médio, o autor apresentou um quadro revelador da precariedade da formação inicial de professores no país.

\section{Tabela 1}

Adequação da formação inicial à área de atuação docente nos anos finais do ensino fundamental e no ensino médio, por região ( $\mathrm{n}=778.000$ docentes), em \%

\begin{tabular}{|l|c|c|c|c|c|c|}
\hline Área & Brasil & Norte & Nordeste & Sudeste & Sul & Centro-Oeste \\
\hline Português & 55,2 & 32,5 & 36,8 & 75,2 & 68,4 & 59,6 \\
\hline Biologia & 51,3 & 32,9 & 42,6 & 57,9 & 58,8 & 61,2 \\
\hline Matemática & 39,3 & 26,5 & 22,3 & 58,8 & 43,4 & 42,9 \\
\hline Educação Física & 38,9 & 14,1 & 15,8 & 67,2 & 56,7 & 31,3 \\
\hline História & 35,5 & 20,4 & 22,7 & 52,5 & 45,5 & 37,1 \\
\hline Química & 34,8 & 18,0 & 20,4 & 52,3 & 44,1 & 27,1 \\
\hline Geografia & 30,1 & 20,2 & 19,3 & 44,3 & 36,1 & 34,6 \\
\hline Inglês & 20,9 & 9,9 & 11,5 & 30,5 & 31,9 & 17,8 \\
\hline Física & 19,1 & 11,0 & 12,6 & 26,7 & 22,1 & 15,9 \\
\hline
\end{tabular}

Fonte: Inep, Censo Escolar 2009. Elaboração: Thiago Alves (2013).

A baixa remuneração docente também foi apontada com uma evidência a favor da ampliação dos investimentos em educação pública. Os baixos valores são visíveis quando se observa a distância entre o salário médio do professor e o salário mínimo ideal, medido pelo Dieese. Como mostrou Pinto, em 2009, apenas o Amapá, o Distrito Federal e Roraima pagaram salários médios, para jornadas de trabalho maiores ou iguais a 30 horas semanais, acima dos $R \$ 2.065,00$ calculados pelo Dieese. 
Se há evidências para justificar a necessidade de ampliação de gastos com a educação pública, não há razões para se desconsiderar a alegação de que é imprescindível estipular prioridades e considerar a eficácia dos investimentos, desde que essa alegação não seja usada para sustentar argumentos contrários ao aumento dos investimentos públicos na educação pública ou para condicionar investimentos em infraestrutura escolar.

Desse modo, as discussões sobre direito à educação e eficácia escolar ligam-se, diretamente, ao debate sobre os instrumentos de verificação desse direito e de responsabilização dos sujeitos que devem assegurá-lo.

\section{Políticas de verificação do direito à educação e de responsabilização de sujeitos}

Apesar da intensidade da discussão, todas as posições participantes do centro do debate assumem, à sua maneira, a premissa de que é preciso haver instrumentos para verificar o cumprimento do direito à educação e para assegurar que os responsáveis pela obrigação de assegurá-lo cumpram esse dever. Alguma forma de avaliação e alguma maneira de responsabilização são partes do chão comum dos debates. As fortes controvérsias a esse respeito, portanto, podem ser lidas como disputas sobre: i) a natureza do direito, i) as formas de registro, medição e avaliação, iii) quem deve ser responsabilizado, iv) as formas e os instrumentos de responsabilização, v) a quem se deve prestar contas; vi) as consequências da responsabilização.

Esse debate não pode ser analisado, atualmente, sem que se leve em conta a presença de um novo sujeito participante do campo político educacional, que alterou substancialmente o jogo de forças e levou os demais participantes a se posicionarem em relação a ele. Freitas (2012) nomeia esse sujeito coletivo de reformadores empresariais, retomando o debate norte-americano. Segundo o autor, esses reformadores atuariam por meio de fundações e institutos empresariais, com apoio de veículos da grande mídia. As posições decisórias no interior desse grupo seriam ocupadas por líderes de grandes grupos empresariais que atuam no país, especialmente aqueles ligados à indústria e aos serviços. Os reformadores empresariais contariam, ainda, com um quadro técnico e científico de apoio: gestores dessas instituições, técnicos de projetos, formuladores de políticas e intelectuais orgânicos que produzem pesquisas educacionais. Assim organizados, esses reformadores conquistaram uma posição dominante no campo político educacional, exercendo forte influência tanto na produção e na difusão de ideias educacionais como no interior do Estado, no Poder Legislativo federal e no Poder Executivo dos três níveis da Federação. Ximenes (2012, 2013) destaca a sua atuação na Câmara dos Deputados, influenciando a formulação da Lei de Responsabilidade Educacional. 
Pode-se indagar se a caracterização do sujeito coletivo "reformadores educacionais" não sugere homogeneidade de posições, ao invés de abrir a possibilidade de se considerar, no lugar desse sujeito homogêneo, um subcampo relativamente heterogêneo, com diferentes concepções educacionais em disputa, entre eles a dos reformadores empresariais, tal como caracterizados por Freitas.

Desde a virada dos anos de 1980 para os de 1990, os institutos e as fundações empresariais atuaram no campo educacional em parceria com algumas organizações não governamentais (ONGs). O campo das ONGs, largamente plural, é formado por associações e fundações, cujo objetivo é representar e organizar setores da sociedade civil para atuar, sem fins lucrativos, em causas públicas; de modo geral, essas instituições definem seus propósitos a partir da lógica da afirmação dos direitos sociais e, em menor escala, civis e políticos. Essas instituições, que não pertencem nem ao Estado nem ao mercado, dependem, contudo, total ou parcialmente, de financiamento público e privado. No que diz respeito ao financiamento privado, tradicionalmente, as relações entre financiadores e financiados são marcadas por tensões e disputas entre concepções educacionais, lógicas de atuação e objetivos diferentes.

Ao longo dos anos de 1990, por sua capacidade técnica e seus conhecimentos especializados, as ONGs financiadas por recursos empresariais contaram com uma larga autonomia operacional em relação aos seus financiadores. Contudo, desde os anos de 2000, cada vez mais os financiadores vêm deixando a posição de repassadores de recursos e verificadores de resultados gerais para, progressivamente, buscarem a autoria das iniciativas que financiam, o que os tem feito interferir cada vez mais no desenho dos projetos e programas, nas suas formas de execução e na sua avaliação.

Para cumprirem com essa nova estratégia de atuação pública, muitas organizações ligadas a empresas vêm montando o seu próprio corpo técnico especializado, recrutando quadros com experiência em ONGs e no poder público. Ao mesmo tempo, quadros de alta direção e grandes acionistas de empresas dedicam cada vez mais parcela de seu tempo, capital social, capital político, prestígio e conhecimentos de marketing e gestão para se constituírem como sujeitos políticos atuantes no campo da política educacional. ${ }^{1}$ Alguns desses quadros dirigentes que passaram a atuar no campo das políticas educacionais foram aqueles que construíram alianças com instituições de ensino superior e centros de pesquisa, especialmente os que reúnem economistas, cujas investigações são orientadas pela teoria do capital humano e influenciadas pelas reformas educacionais baseadas nas políticas de accountability. A aliança selada entre esses novos reformadores empresariais e os economistas da educação consolidou uma nova e poderosa posição com o campo político educacional. 
No universo das ONGs, o reposicionamento das organizações empresariais mudou os termos do diálogo e da disputa entre financiadores e financiados. Assim, muitos financiados viram sua autonomia reduzida e, em alguns casos, passaram a lutar contra a ameaça de serem instrumentalizados para a realização dos propósitos dos financiadores, que são definidos e formalizados em planejamentos estratégicos. Por vezes, ainda, antigos financiadores, agora contando com profissionais especializados, passaram a realizar projetos diretamente, sem a necessidade de "parceiros técnicos".

Recém-chegados no campo da política educacional e precisando ser reconhecidos como interlocutores legítimos em um debate em curso, os reformadores empresariais buscam alianças, por um lado, como a realizada com uma corrente da economia da educação, e, por outro lado, são forçados a se posicionar em relação a questões e perspectivas distintas das suas, disputando com elas dentro e fora de seu campo imediato de atuação. ${ }^{2}$ Desse modo, a posição dos reformadores educacionais é constituída a partir de um jogo de forças, sendo que a perspectiva que articula a teoria do capital humano ao gerencialismo e à concorrência como princípio regulador de políticas públicas disputa primazia com outras perspectivas, orientadas pela afirmação de direitos por meio do investimento social privado. Essas diferentes perspectivas coexistem e se relacionam nesse universo complexo. A disputa entre essas orientações é recente, ainda está em curso e seus resultados carecem de ser descritos e interpretados.

No campo mais amplo da política educacional, opõem-se aos reformadores empresariais os educadores profissionais, grupo associado mais comumente a pesquisadores de faculdades de Educação, sindicatos de docentes e de trabalhadores da Educação, além de determinados movimentos sociais e organizações da sociedade civil. Almeida (2008) situa as raízes desse grupo nos educadores que organizaram a Associação Brasileira de Educadores, em 1924, e as Conferências Nacionais de Educação a partir da década de 1930. Segundo a autora, até os anos de 1940, os educadores profissionais tiveram atuação decisiva na formulação de marcos legais, instituições estatais e políticas específicas que tornaram o Estado responsável pela escolarização obrigatória.

A perda de hegemonia dos educadores profissionais começou a ocorrer no momento em que a educação deixou de ser pensada, primordialmente, como instrumento de construção da nação para ser pensada como instrumento de desenvolvimento econômico. O processo que Almeida (op. cit.) chama de "assalto à educação pelos economistas" se realiza entre os anos de 1950 e 1970, consolidando-se nas políticas implementadas durante o governo militar. Se, posteriormente, durante a abertura política, com a recuperação de direitos civis e políticos que haviam sido cerceados, as novas gerações de educadores profissionais recuperaram 
poder e influência, nos anos de 1990, a emergência de reformadores empresariais aliados a economistas resultaria em um novo "assalto".

Os reformadores empresariais assumem, como princípio geral, a necessidade e a pertinência da transferência, para a formulação e a gestão de políticas públicas, das lógicas da gestão empresarial e da concorrência em um mercado. Combinadas, essas duas lógicas levariam à eficácia dos agentes e, globalmente, dos sistemas.

As políticas defendidas por parte expressiva de suas lideranças contemplam as seguintes medidas que, associadas, caracterizam a accountability de tipo hard: avaliação externa de escolas e redes, metas de resultados educacionais aferidos por avaliações externas, autonomia de gestão para as escolas, concorrência entre agentes educacionais, prêmios e punições para profissionais das escolas. No Brasil, essas medidas tendem a vir acompanhadas da busca pela forte padronização das práticas pedagógicas. Alguns reformadores, ainda, defendem formas de transferência, para entidades de direito privado, da gestão de equipamentos públicos e da oferta direta de serviços financiados pelo Estado.

Essas políticas são meios e não o fim almejado. Este pode ser definido como o aprimoramento do capital humano do país, tal como apontado na teoria econômica desde os trabalhos pioneiros de Theodor Schultz (2012). Neste quadro teórico, os gastos em educação podem ser pensados como investimentos dos indivíduos e dos Estados que repercutirão na renda individual e na riqueza nacional. Portanto, a educação passa a ser definida - e justificada - em função de seus resultados econômicos. Atualmente, por conta das características do capitalismo contemporâneo, com a concorrência em nível global e a pressão por aumento constante de produtividade a partir da incorporação de inovações tecnológicas e do desenvolvimento de formas complexas de gestão, uma das condições para que a economia brasileira seja competitiva seria, alega-se a partir desse quadro teórico, o investimento massivo na formação de capital humano.

Esta posição não esteve representada nos debates do IV SEB.

A accountability, em versão light, também é instrumento de outra posição, distinta da dos reformadores empresariais. Muito embora apresente diferenças, essa outra posição se relaciona com a dos reformadores empresariais e disputa com eles legitimidade no interior do campo no qual atuam. Nessa versão, não são preconizadas punições prescritas na versão hard, como o fechamento de escolas, a remoção de professores, a estagnação na carreira ou a perda do emprego.

Também na versão light, a accountability é um instrumento para realização de fins mais amplos. Contudo, seus representantes não adotam a teoria do capital humano como a referência teórica para a definição e justificação da finalidade da 
educação escolar. Seus fins estão ligados à realização do direito à educação com qualidade e equidade e suas matrizes remontam, mais comumente, ao liberalismo político de autores como John Rawls e Amartya Sen.

A qualidade é definida em função do acesso à escola, da permanência com aprovação e da aprendizagem de habilidades e conteúdos curriculares, cujo valor e importância não são definidos em função de resultados econômicos, mas em termos do desenvolvimento de capacidades intelectuais determinadas que permitissem às pessoas participar autonomamente da vida social e desenvolver seus projetos de vida.

A equidade, por sua vez, é definida - e medida - por referência à igualdade entre a distribuição dos desempenhos escolares de indivíduos agrupados segundo determinadas características sociais. Assim, a diferença de desempenho entre indivíduos é aceita, desde que situada acima de patamares mínimos de qualidade que devem ser universalizados. O que não se aceita é que haja diferenças entre distribuições de grupos de indivíduos definidos em função, por exemplo, de classe social, raça, gênero ou local de moradia. Para assegurar a equidade, esses autores preconizam, por um lado, a universalização da oferta educacional de qualidade e, por outro, políticas de discriminação positiva para que grupos tradicionalmente desfavorecidos possam ter acesso aos saberes escolares. SEB.

Representantes dessa segunda posição, no Brasil, estiveram presentes no IV

Nigel Brooke e José Francisco Soares reconhecem efeitos negativos das políticas de accountability, por exemplo, no Chile e nos EUA. No que diz respeito aos EUA, reconhecem a validade de estudos recentes que mostram sua baixa eficácia e sua contribuição para o aumento de desigualdades. Por que, então, defendem-nas para a realidade brasileira?

Em sua exposição no IV SEB, Brooke (2013) alegou que as políticas produziriam resultados e assumiriam significados distintos de acordo com as diferenças históricas, culturais e institucionais dos países e das regiões em que são implantadas. Nos EUA, a forte sobrecarga de iniciativas de responsabilização, um traço da cultura daquele país, teria retirado as condições para a eficácia dessas políticas e fortalecido seus efeitos indesejados, como a burla e o aumento de desigualdades.

No Brasil, onde não haveria essa sobrecarga e onde as condições históricas, culturais e institucionais são diferentes, elas poderiam produzir efeitos positivos, promovendo qualidade e equidade. Muito embora se reconheça que é possível haver efeitos colaterais indesejados também entre nós, não haveria evidências de que sejam significativos o bastante para que se negue, em bloco, a legitimidade e a validade 
dessas políticas. Ao contrário, exemplos de estados e municípios que se utilizaram de resultados de avaliações seguidas de premiações por bons resultados serviriam de evidências para justificar essa posição, com destaque para o caso do Ceará.

Com esse argumento, Brooke procura refutar as duas linhas de crítica à pertinência dessas políticas no Brasil: primeiro, recusando a validade da transferência direta para o país das evidências de ineficácia e de efeitos indesejáveis verificadas nos EUA e outros países; segundo, lançando dúvidas sobre a extensão dos efeitos indesejados verificados no Brasil em face dos efeitos positivos.

Freitas assume posição bastante diferente. Muito embora reconheça que essas políticas podem produzir a elevação de resultados de aprendizagem quando implantadas em realidades educacionais muito desorganizadas e com resultados muito baixos, ele sustenta que os ganhos teriam fôlego curto. Uma vez cumprida essa primeira fase de estruturação das redes, logo se produziriam os resultados indesejáveis conhecidos nos países em que estão implementadas há mais tempo, como a ineficácia, o aumento das desigualdades e a redução curricular.

Para Freitas, as evidências norte-americanas, bem como as chilenas, mostrariam realidades para as quais nos encaminhamos e, sendo assim, deveriam orientar a revisão dessas políticas entre nós. Um de seus argumentos para sustentar essa assertiva é que essas políticas se baseiam em certos princípios com validade geral, como a falsa suposição de homologia entre o funcionamento das organizações de mercado e o Estado democrático de direitos. No mercado concorrencial, a eficiência dos agentes mais fortes se dá em detrimento da falência ou da ineficiência de outros; já as políticas públicas de Estado obedeceriam a uma lógica bem distinta, a da universalização de direitos, em que não cabem a eficiência e o êxito de alguns à custa de outros. Como essa falsa suposição mobiliza duas instituições de validade geral - Estado democrático de direitos e mercado -, as evidências dos efeitos indesejáveis decorrentes dela teriam, igualmente, validade geral.

No Brasil, sustenta Freitas, exceção feita às redes desestruturadas e com baixos resultados, as políticas de responsabilização light não têm surtido os efeitos desejados, mostrando-se ineficazes, como evidenciaria a experiência da rede estadual de São Paulo. Mesmo nesses casos em que as bonificações são dadas a toda a equipe das escolas sob a alegação de que, assim, induziriam à colaboração, essas políticas terminariam por produzir efeitos contrários: reforçariam mecanismos de quase mercado educacional produzidos pela concorrência entre as escolas por alunos que melhor respondam às exigências comportamentais e de desempenho acadêmico, o que contribui para o aprofundamento de desigualdades.

A crítica de Freitas traz à tona o papel que as interações entre as escolas desempenham na organização de cada estabelecimento e na produção de desigualdades. 
Do ponto de vista teórico, pode-se afirmar que essas redes de relações de interdependência e disputa são importantes para a compreensão do modo de organização e das estratégias de cada unidade escolar, bem como das práticas educativas das famílias (BEN AYED; BROCOLICHI, 2001; VAN ZANTEN, 2005, 2006, 2009).

Há evidências de que a concorrência entre escolas por alunos que melhor correspondem a suas exigências contribuiria para a produção de desigualdades. Quando algumas escolas têm maiores possibilidades de selecionar esses alunos, garantindo assim melhores condições de funcionamento e melhor desempenho, outras escolas, mais fragilizadas, concentrariam alunos que são mais desafiadores, tendo mais dificuldades para obter desempenhos elevados. Os bons desempenhos de algumas poucas, portanto, seriam obtidos com o custo das dificuldades e do baixo desempenho de outras, aprofundando as desigualdades educacionais (ALVES; BATISTA; ÉRNICA, 2012; ÉRNICA; BATISTA, 2012; KOSLINSKI; COSTA, 2009; VAN ZANTEN, 2005, 2006; YAIR, 1996).

Esses mecanismos, porém, podem existir mesmo onde não há políticas deliberadas de estímulo à concorrência entre ofertantes e entre demandantes de serviços educacionais.

Esse é o caso, por exemplo, da França, onde o espaço de concorrência educacional foi instaurado pela articulação de processos distintos, analisados por Ben Ayed e Brocolichi (2001). O primeiro processo se deu a partir de transformações no interior do sistema escolar. A massificação escolar, ao invés de democratizar o direito à educação, afirmam os autores, produziu um quadro de segregação social e hierarquização dos estabelecimentos, aprofundando as desigualdades educacionais em novas bases. Ao mesmo tempo, as famílias com maiores recursos econômicos e culturais passaram a evitar os estabelecimentos que atendiam as famílias populares. Por sua vez, as políticas de descentralização administrativa e de autonomia dos estabelecimentos favoreceram, além da estratificação da oferta educacional segundo o perfil dos alunos, processos de concorrência entre escolas por alunos mais adequados as suas expectativas.

O segundo processo se deu posteriormente, com as políticas sustentadas na premissa de que a concorrência no quase mercado educacional deveria ser o princípio regulador do sistema educacional, o que aprofundou os mecanismos de concorrência pré-existentes. Combinados, esses dois processos instauraram uma espiral de competição e segregação social no espaço escolar que ampliou a produção de desigualdades educacionais.

Analisando o caso brasileiro, Mariane Koslinski (2013) apresentou no IV SEB um balanço de pesquisas que relacionam desigualdades educacionais a desigualdades socioespaciais. Baseando-se, sobretudo, em pesquisas sobre os casos do Rio de Janeiro, mas dialogando com estudos sobre Belo Horizonte e São Paulo, a autora aponta, nessas metrópoles, processos semelhantes aos verificados nas pesquisas internacionais. 
As famílias de classe média, que têm mais recursos econômicos, sociais e culturais e podem fazer mais escolhas a partir das oportunidades existentes no quase mercado escolar, tendem a ser escolhidas pelas escolas e exercem estratégias de evitação de territórios, escolas e populações estigmatizadas. As famílias populares, por sua vez, com menos recursos para fazer escolhas e tendendo a ser evitadas pelas classes médias e pelas escolas destinadas a essas classes, terminariam segregadas em certos territórios e estabelecimentos que, por sua vez, reuniriam condições mais precárias de gestão e oferta educacional.

Contudo, para o caso brasileiro, ainda há poucas pesquisas analisando o impacto das políticas de responsabilização sobre a estrutura e o funcionamento do quase mercado educacional. O caso da rede municipal de Teresina (ÉRNICA, 2012) ilustra como políticas que estruturam e geram resultados efetivos nas escolas de uma só rede podem, em um contexto de oferta desigual e intensa concorrência entre famílias por escolas e entre escolas por alunos, integrar mecanismos de produção de desigualdades.

De sua parte, o noticiário nacional traz, volta e meia, indicações de que políticas de accountability podem estimular os mecanismos do quase mercado educacional, produzindo efeitos indesejados. Em maio de 2013, o Ministério Público de Goiás recebeu a denúncia de que escolas da rede estadual deste estado estariam expulsando veladamente alunos que poderiam rebaixar o seu desempenho no Ideb (PORTAL G1 GOIÁS, 2013), pois naquela rede o cumprimento de metas de desempenho definidas com base nesse indicador gera bonificações em dinheiro para as escolas. Em Sorocaba (SP), a escola com a maior média em 2011 no indicador de qualidade da rede estadual (Idesp) foi acusada de fraude, pois os professores teriam ajudado os alunos a responder as questões da prova, visando o recebimento de bônus. Com a denúncia, toda a equipe gestora da escola foi removida e uma investigação foi aberta; em crise, no ano seguinte a escola obteve um baixo resultado, um dos piores de sua região (O ESTADO DE S. PAULO, 2013).

Muito embora não tenhamos pesquisas sistemáticas sobre a extensão desse fenômeno no Brasil, os casos de Goiás e São Paulo sugerem a existência de uma inversão típica dos mecanismos de mercado: o fim tornando-se meio. Transformado em meio para obtenção de recursos para a escola, a melhoria artificial dos indicadores revelaria um grau avançado do processo de sua reificação: após ser afirmado como uma realidade válida por si, passaria a regular os processos educacionais e acabaria por distorcê-los ou corrompê-los.

Está em aberto o debate sobre os efeitos desejáveis (qualidade e equidade) e os efeitos indesejáveis (como ineficácia, elevação de desigualdades e redução curricular) das políticas de responsabilização. No plano internacional, afirmou-se que são poucas as pesquisas comparadas que abordam as mediações pelas quais as mesmas diretrizes 
de políticas produzem efeitos diversos em contextos distintos. No que diz respeito ao Brasil, são igualmente poucas as pesquisas empíricas que mobilizam dados quantitativos e qualitativos para analisar a extensão e a natureza dos efeitos dessas políticas. Dessa forma, é prudente que o campo científico, além de contribuir aprofundando essas investigações, reivindique cautela diante das políticas que podem intensificar os mecanismos de quase mercado produtores de desigualdades.

\section{Por um chão comum}

Os debates do IV SEB sobre direito à educação, oferta educacional de qualidade e sobre as políticas de accountability, tratados neste trabalho, trazem à tona elementos de nosso chão comum.

Em primeiro lugar, a capacidade das escolas assegurarem a equidade no acesso aos saberes escolares a todos os grupos sociais, em parâmetros de qualidade socialmente definidos, emergiu como um valor comum, como resultado desejado que pode ser expresso pelas ideias de equidade e qualidade. Por outro lado, a restrição curricular, a ineficácia escolar e as desigualdades educacionais foram consensualmente definidas como resultados indesejáveis.

Há, portanto, uma agenda comum de investigação que, orientada por essas preocupações, pode ser expressa por meio de perguntas como: Quais são as desigualdades educacionais brasileiras? O que as explica? Como as políticas podem mitigá-las ou aprofundá-las?

Esses consensos globais podem contribuir para a definição de critérios públicos, validados por diferentes sujeitos, para a elaboração e a avaliação de políticas. Acatar politicamente essas ideias compartilhadas não impede a necessária controvérsia quando o debate se aprofunda ou se desloca para outras direções. Ao contrário, a assunção do chão comum pode alimentar a formulação de novas questões. Nesse âmbito, são várias as questões em aberto, sendo que algumas requerem soluções científicas e outras só poderão encontrar respostas políticas.

Um primeiro tema em discussão diz respeito à definição de qual deve ser - e de qual é - o significado social da cultura comum que as instituições escolares devem transmitir e difundir, cultura da qual fazem parte as capacidades cognitivas aferidas nas matrizes de avaliação. São escassas as pesquisas sobre os estados e os municípios que tomem por objeto os significados da educação efetivamente transmitida pelas escolas, em cada contexto, entendidos para além da matriz de habilidades que guia as provas padronizadas.

Outro campo de questões em aberto diz respeito às políticas mais adequadas a realizar esses objetivos gerais. Quais as diretrizes desejadas para políticas que procuram 
assegurar o direito à educação de qualidade, incluindo os modos de verificação do seu cumprimento e a responsabilização dos agentes? Como parte dessa questão geral, pode-se perguntar: Como as atividades de ensino e aprendizagem podem ser organizadas mais adequadamente às possibilidades e necessidades das famílias populares, de modo que elas possam se apropriar dessa cultura que se quer transmitir pela escola?

A definição da cultura geral a ser transmitida pela escola e das políticas de sua efetivação, por serem definições políticas, não à toa suscitam debates intensos. No que se refere às políticas de accountability, não sabemos quais são os seus efeitos no Brasil. Porém, a literatura disponível, brasileira e internacional, traz evidências suficientes para afirmarmos que os mecanismos do quase mercado educacional precisam ser regulados, buscando-se a qualidade e a equidade e evitando as desigualdades e outros efeitos indesejados. Mas qual regulação implantar? Esta é outra questão aberta.

Por fim, no que diz respeito aos fóruns de discussão dessas questões, o IV SEB deu provas da importância desse terreno de interface entre os campos político e científico, onde as políticas são avaliadas sob critérios científicos e as pesquisas são chamadas a dialogar com as necessidades daqueles que formulam e executam políticas. Como tantas vozes afirmaram, a controvérsia pública nesse terreno híbrido, com a ampla participação de todos os sujeitos concernidos, é a melhor forma de produção de sentido sobre nossa realidade educacional. $\mathrm{O}$ fortalecimento do caráter público do debate, assim, é um meio importante de prestação de contas à sociedade sobre o que se quer para a educação e o que se pensa sobre ela. Por isso, é um elemento central da regulação democrática dos projetos de educação pública voltados à difusão do direito ao acesso aos saberes escolares.

\section{Notas}

1. A reportagem da revista Época Negócios, em sua edição de 19/10/2012, intitulada "A turma da escola", ilustra esse processo, mostrando a aliança entre grandes acionistas de grupos empresariais, quadros de alta direção dessa empresas e técnicos com experiência no poder público na atuação no campo educacional. A reportagem dá destaque à participação ativa desse grupo na viabilização do programa Educação - Compromisso de São Paulo, da Secretaria de Educação desse estado.

2. Um exemplo dessa disputa é o prefácio de Marcos de Barros Lisboa (2009), no qual, para defender a pertinência do desenvolvimento das pesquisas quantitativas em educação, o autor desfere adjetivações desqualificadoras a quem assume posição contrária à sua.

\section{Referências}

ALMEIDA, A.M.F. O assalto à educação pelos economistas. Tempo Social - Revista de Sociologia da USP, São Paulo, v. 20, n. 1, p. 163-178, jun. 2008.

ALVES, L.; BATISTA, A.A.G.; ÉRNICA, M. Processos velados de seleção e evitação de alunos em escolas públicas. São Paulo: Cenpec, set. 2012. (Informe de Pesquisa n. 6). 
ALVES, T. Estratificação das oportunidades educacionais no Brasil: contextos e desafios para a oferta de ensino em condições de qualidade para todos. In: SEMINÁRIO DA EDUCAÇÃO BRASILEIRA, 4. Campinas: Cedes, 2013.

BEN AYED, C. Quelles politiques de responsabilité pour lutter contre les inégalités socio-spatiales d'éducation: l'exemple de la France. In: SEMINÁRIO DA EDUCAÇÃO BRASILEIRA, 4. Campinas: Cedes, 2013.

BEN AYED, C.; BROCCOLLICHI, S. Quelques remarques concernant les usages de la notion "marché" dans le champ scolaire. Revue Questions Éducatives - l'école et ses marges, Université de Saint Étienne, n. 20, p. 17-55, 2001.

BROOKE, N. Políticas de responsabilização: buscando o diálogo. In: SEMINÁRIO DA EDUCAÇÃO BRASILEIRA, 4. Campinas: Cedes, 2013.

EDITORIAL. Educação \& Sociedade, Campinas, v. 34, n. 122, p. 15-22, jan.-mar. 2013.

ÉPOCA NEGÓCIOS. A turma da Escola. Época Negócios, São Paulo, n. 66, p. 47-61, ago. 2012.

ERNICA, M. Desigualdades educacionais no espaço urbano: o caso de Teresina. São Paulo: Cenpec, out. 2012. (Informe de Pesquisa n. 3).

ÉRNICA, M.; BATISTA, A.A.G. A escola, a metrópole, a vizinhança vulnerável. Cadernos de Pesquisa, São Paulo, v. 42, n. 146, maio/ago. 2012.

FREITAS, L.C. Crítica às políticas de responsabilização no Brasil. In: SEMINÁRIO DA EDUCAÇÃO BRASILEIRA, 4. Campinas: Cedes, 2013.

FREITAS, L.C. Os reformadores empresariais da educação: da desmoralização do magistério à destruição do sistema público de educação. Educação E Sociedade, Campinas, v. 33, n. 119, p. 379-404, abr.-jun. 2012.

KOSLINSKI, M.C. Desigualdades educacionais nas metrópoles brasileiras: o impacto da organização do território e das políticas educacionais. In: SEMINÁRIO DA EDUCAÇÃO BRASILEIRA, 4. Campinas: Cedes, 2013.

KOSLINSKI, M.C.; COSTA, M. Competing for public schools in Rio de Janeiro reflexions on a hidden quasi-market. In: Penser les marches scolaires. Genève: Rappe Université de Genève, 2009. p. 1-22.

LISBOA, M.B. Prefácio. In: VELOSO, F. et al. Educação básica no Brasil: construindo o país do futuro. Rio de Janeiro: Campus/Elsevier, 2009.

O ESTADO DE S. PAULO. Escola suspeita de fraude tem nota baixa no Saresp. O Estado de S. Paulo, São Paulo, 1 abr. 2013. Disponível em: <http://www.estadao.com.br/ noticias/geral,escola-suspeita-de-fraude-tem-nota-baixa-no-saresp,1015689,0.htm>. Acesso em: 6 jun. 2013. 
PORTAL G1 GOIÁS. Escolas estaduais são suspeitas de expulsar alunos para melhorar Ideb. Portal G1 Goiás, 25 maio 2013. Disponível em: <http://g1.globo.com/goias/ noticia/2013/05/escolas-estaduais-sao-suspeitas-de-expulsar-alunos-para-melhorarideb.html>. Acesso em: 6 jun. 2013.

PINTO, J.M.R. Em busca de um financiamento que assegure um patamar básico de qualidade para todos. In: SEMINÁRIO DA EDUCAÇÃO BRASILEIRA, 4. Campinas: Cedes, 2013.

SOARES NETO, J.J. et al. Uma escala para medir a infraestrutura escolar. Estudos em Avaliação Educacional, São Paulo, v. 24, n. 54, p. 78-99, jan./abr. 2013.

SOARES, J.F. Além do nível socioeconômico dos alunos: o impacto de outras desigualdades entre escolas de educação básica. In: SEMINÁRIO DA EDUCAÇÃO BRASILEIRA, 4. Campinas: Cedes, 2013.

SCHULTZ, T.W. O impacto da Teoria do Capital Humano. In: BROOKE, N. Marcos históricos na reforma da educação. Belo Horizonte: Fino Traço, 2012.

VAN ZANTEN, A. Efeitos da concorrência sobre a atividade dos estabelecimentos escolares. São Paulo. Cadernos de Pesquisa, São Paulo, v. 35, n. 126, p. 565-593, set./dez. 2005.

VAN ZANTEN, A. Compétition et fonctionnement des établissements scolaires: les enseignements d'une enquête européenne. Revue Française de Pédagogie, Paris, n. 156, p. 9-17, juil./sept. 2006.

VAN ZANTEN, A. Le choix des autres: jugements, stratégies et ségrégations scolaires. Paris: Actes de la Recherche en Sciences Sociales, n. 180, déc. 2009. p. 24-36.

XIMENES, S. Responsabilidade educacional: concepções diferentes e riscos iminentes ao direito à educação. Educação \& Sociedade, Campinas, v. 33, n. 119, p. 353-377, abr.jun. 2012.

XIMENES, S. Responsabilidade educacional: uma crítica às concepções em disputa. In: SEMINÁRIO DA EDUCAÇÃO BRASILEIRA, 4. Campinas: Cedes, 2013.

YAIR, G. School organization and market ecology: a realist sociological look at the infrastructure of school choice. Britsh Journal of Sociology of Education, London, v. 17, n. 4, p. 453-471, 1996.

Recebido em 13 de setembro de 2013.

Aprovado em 6 de dezembro de 2013. 
